\title{
Impact of JAK Inhibitors in Pediatric Patients with STAT1 Gain-of-Function (GOF) Mutations - 10 Children and Review of the Literature
}

\section{Angela Deya ( $\sim$ adeya@hsjdbcn.es )}

Hospital Sant Joan de Déu Servei d'Al-lèrgia i Immunologia Clínica: Hospital Sant Joan de Deu Servei d'Allergia i Immunologia Clinica https://orcid.org/0000-0002-8026-7674

Jaques Gabriel Riviere

Persio Roxo-Junior

Jan Ramarkers

Marketa Bloomfield

Paloma Guisado Hernandez

Pilar Blanco Lobo

Soraya Regina Abu Jamra

Ana Esteve-Solé

Veronika Kanderova

Ana Garcia-Garcia

Mireia Lopez Corbeto

Natalia Martinez Pomar

Andrea Martin Nalda

Laia Alsina

Olaf Neth

Peter Olbrich

https://orcid.org/0000-0001-9853-7903

\section{Research Article}

Keywords: Primary immunodeficiency disease; inborn errors of immunity, pediatrics, children, JAK-STAT pathway, chronic mucocutaneous candidiasis, ruxolitnib, baricitinib, STAT1 GOF, JAK inhibitors

Posted Date: January 20th, 2022

DOI: https://doi.org/10.21203/rs.3.rs-1231747/v1

License: (c) (i) This work is licensed under a Creative Commons Attribution 4.0 International License. Read Full License 


\section{Abstract}

Introduction. Since the first description of gain of function (GOF) mutations in Signal Transducer and Activator of Transcription (STAT) 1, more than 300 patients have been described with a broad clinical phenotype including infections and severe immune dysregulation. Whilst Jak inhibitors (JAKinibs) have demonstrated benefits in several reported cases, its indications, dosing and monitoring remain to be established.

Methods. A retrospective, multicenter study recruiting pediatric patients with STAT1 GOF under JAKinib treatment was performed and, when applicable, compared with the available reports from the literature.

Results. Ten children (median age 8.5y (3-18), receiving JAKinibs (ruxolitinib $(n=9)$ and baricitinib $(n=1)$ ) with a median follow-up of $18 \mathrm{~m}$ (2-42) from 6 inborn errors of immunity (IEI) reference centers were included. Clinical profile and JAKinib indications in our series were similar to the previously published 14 pediatric patients. 9/10 (our cohort) and 14/14 patients (previous reports) showed partial or complete responses. The median immune deficiency and dysregulation activity scores were 15.99 (5.2-40) pre and 7.55 (3-14.1) under therapy $(p=0.0078)$. Infection, considered a likely adverse event of JAKinib therapy, was observed in $1 / 10$ patient; JAKinibs were stopped in $3 / 10$ children, due to hepatotoxicity, pre HSCT and absence of response. Conclusions. Our study supports the potentially beneficial use of JAKinibs in patients with STAT1 GOF, in line with previously published data. However, consensus regarding their indications and timing, dosing, treatment duration and monitoring, as well as defining biomarkers to monitor clinical and immunological responses, remains to be determined, in form of international prospective multicenter studies using established IEI registries.

\section{Introduction}

Since its first description in 2011 [1,2], gain of function (GOF) mutations in Signal Transducer and Activator of Transcription (STAT) 1 have been identified in more than 300 patients worldwide. Most mutations are localized in theSrc homology 2(SH2) or DNA binding domains[3].STAT1 is mainly activated via the binding of type I, II and III interferons to their respective cytokine receptors, resulting in JAK1, JAK2, JAK3 activation and phosphorylation, followed by the recruitment of STAT molecules from the cytoplasm. The STAT molecules are then phosphorylated (pSTAT) and form homo or heterodimers that translocate to the nucleus where they regulate gene transcription[4]. STAT1 GOF patients show higher PSTAT1 levels after stimulation with activating cytokines (mainly interferons), which represents the molecular hallmark of the disease [1,2]. Whether this is the result of altered dephosphorylation dynamics, prolonged binding of STAT1, increased availability of total STAT1 molecules or other mechanisms remains to be elucidated[1,2,5].

From a clinical perspective, the phenotype of STAT1 GOF patients is broadly heterogenous. The most common symptom is early onset chronic mucocutaneous candidiasis (CMC). However, (myco-) bacterial, viral and fungal infections, (multiorgan) autoimmunity or autoinflammation, vascular malformations and 
malignancies have also been reported [6]. The management of these complex patients is therefore challenging and often requires a balanced use of antimicrobial and immunosuppressive therapies. Hematopoietic stem cell transplantation (HSCT) is a potential curative procedure but graft failure as well as secondary graft rejection are common and resulted in a $40 \%$ overall survival rateonly[7].

In recent years, case reports have described JAK inhibition as an effective targeted treatment option for STAT1 GOF patients $[3,8,9,10,11]$. JAK inhibitors (JAKinibs) are small molecules interfering with the process of cytokine-dependent JAK activation. In patients with STAT1 GOF,ruxolitinib ${ }^{\circledR}(\mathrm{RXL})$, as well as baricitinib $\AA$, have been used[12,13]. However, the clinical experience with these drugs in the field of inborn errors of immunity (IEI) is still limited and important questions including indications, dosing and monitoring remain, especially in pediatric patients.

Here, we present the experience with JAK inhibition in 10 pediatric STAT1 GOF patientsunder the care of sixIEI reference centers. We provide detailed information regarding indications, dosing regimens, side effects, complications as well as the clinical effects on the most relevant disease manifestations. In addition, we reviewed all previously published pediatric STAT1 GOF cases treated with JAKinibsand compared main characteristics with our cohort, when applicable.

\section{Methods}

\section{Patients and study design}

Pediatric patients (age $<18$ years at treatment initiation) with functionally confirmed or previously described STAT1 GOF mutations receiving JAKinibsfor a minimum of two consecutive months were recruited from six IElreference centers. The protocol of this study was reviewed and approved by theethics committee "HospitalesUniversitarios Virgen Macarena y Virgen del Rocío" (PI19/01471; 0641-N-20) and where applicable by the local ethics committeesof the participating centers. Informed consents were obtained from study participants and/or their legal guardians according to the requirements of the local ethics committees.

\section{Data collection}

A questionnaire (available on reasonable request) designed to retrospectively collect demographic, molecular and clinical data was prepared and distributed. Additionally, the responsible physicians were contacted to verify and discuss the extracted data for each patient.

Genetic analysis and functional variant validation

All patients were tested at their corresponding institutions. Sanger sequencing was performed for all patients and novel variants were functionally validated by means of STAT1 phosphorylation assays as previously described $[1,2]$.

$\underline{\text { Response evaluation }}$ 
For our cohort, the attending physicians were asked to categorize the clinical response of their patients before and after starting JAK inhibition in the following categories: (1) complete response, (2) partial response, (3) no response, (4) manifestation not present. Due to the limited data information extracted from the literature review, the treatment response of the published cases wascategorized as as follows: (1) resolution of symptoms or partial response, (2) manifestation present in the patient but response to JAKinib not specified, (3) transitory response (4) no response, (5) manifestation not present.

Immune deficiency and dysregulation activity_(IDDA-Score).

The IDDA score is a promising tool to assess disease activity and burden in the setting of immune deregulatory diseases $[14,15]$. It allows for intraindividual, longitudinal monitoring by using a number of relevant clinical parameters. Items required to calculate the score were part of a questionnaire. The patients' scores were calculated as previously described [14] by their attending physician before starting JAK inhibition (retrospectively) and at the last clinical follow up.

\section{Literature review}

STAT1 GOF patients less than 18 years old treated with JAK inhibitors were identified via a systematic literature search in EMBASE and PUBMED using the following search terms: primary immunodeficiency disease, inborn errors of immunity, pediatrics, children, JAK-STAT pathway, chronic mucocutaneous candidiasis, STAT1 GOF, JAK inhibitors, STAT1, gain of function, JAKinib, JAK inhibitor, ruxolitinib and baricitinib. All articles and references were screened for other eligible publications. To avoid case duplications those patients mentioned in more than one publication were identified and relevant data was extracted from all corresponding publications (Table S-1).

\section{$\underline{\text { Statistical analysis }}$}

Variables were described as percentages or median values with ranges (min-max), respectively. Normality for quantitative variables was evaluated using the Shapiro-Wilk test. For inferential statistics, the Wilcoxon test was applied. A p-value lower than 0.05 was considered statistically significant.

\section{Results}

Baseline characteristics and disease manifestations before starting JAK inhibition

Ten patients were included in our cohort (Table 1). Of note, patient 9 (P9) was treated with ruxolitinibduring two time periods. Whilst the first episode has been previously published [11], we here provide extended data on the second treatment course. The baseline characteristics of the cohort are presented in Table 1 and a detailed description for each patient is given in Table S-1.

The median age of disease onset and at study entry of our cohort was 6 months (range $1 \mathrm{~m}-48 \mathrm{~m}$ ) and 8.5 years $(3 y-18 y)$, respectively, with a predominance of female patients $(8 / 10)$. 
Infections were common andCMC was present in all patients, being the only infectious manifestationin two of them. Bacterial infections, mainly of the lower respiratory tract, were frequently reported; $6 / 10$ patients developed bronchiectasis. At least one episode of symptomatic herpesviridae infection was observed in 6 out of 10 children prior starting JAK inhibition.

All patients showed at least one autoimmune and/or autoinflammatory manifestation. Oral aphthae $(8 / 10)$ were the most common feature, followed by scleritis/keratitis $(4 / 10)$ and autoimmune cytopenia $(3 / 10)$. Lymphoproliferation was not observed inour cohort. One patient suffered from pulmonary hypertension due to a chronic interstitial lung disease. Failure to thrive was noted in 3/10 patients and in two patients aneurysms of the central nervous system were identified.

Features of antibody deficiency were reported for $5 / 10$ patients. $6 / 10$ patients received immunomodulatory therapy in form of immunoglobulin replacement treatment (IGRT).

A systematic literature review identified 14 additional pediatric STAT1 GOF patients under JAKinib therapy (see Table 1 and Table S-1). Median age was 10y (7m-17y), 50\% were female. Almost all children suffered infections, CMC (13/14) and bacterial (11/14) infections being most commonly reported. Autoimmune/autoinflammatory complications were often reported, with cytopenia being the most common (9/14), followed by enteropathy (8/14) and autoimmune hepatitis (6/14). One patient presented with lymphoproliferation and most showedfailed to thrive $(9 / 14)$.

\section{JAKinib treatment indications and monitoring}

In our cohort, 9 patients received ruxolitinib and one patient baricitinib. Dosing is detailed for each patient in TableS-1. The main reasons to start JAK inhibition were immune dysregulation (10/10), manifested asoral aphthae, keratitis, enteropathy and autoimmune hepatitis, followed by uncontrolled CMC $(6 / 10)$. The baseline studies performed prior treatment initiation and during the follow-up, as well as the monitoring frequency of the treatment, are detailed in Table S-1 and Table S-2. The median treatment follow-up time for our cohort was 18 months (2-42 months); with a total follow-up timeof 197 months.

Although specific information was not available for all previously published cases the main reason to start treatment wereautoimmune complications.

\section{$\underline{\text { JAKinib treatment responses }}$}

An overview summarizing the treatment responses for each disease manifestation in our patients and previously published pediatric cases is shown in Figure 1. Under JAKinib therapy, most clinical manifestations showed at least partial improvement except forP2,in whom CMC and stomatitis/aphthae persisted despite good treatment adherence. Time to response after treatment initiation appears to depend on the clinical manifestation. In our cohort, early responses were observed for cytopenia (1-2 weeks), CMC (1-8 weeks), dermatitis (2-4 weeks) and improvement of oral aphthae and enteropathy after 6-8 weeks of treatment. In contrast, keratitis, autoimmune hepatitis or pulmonary hypertension required prolonged treatment (4-8 months) and cerebral aneurysms did not show any treatment responses.In the 
reviewed cases from the literaturethe variable "time to response" was not consistently reported [Table S-2]. In those cases where specific information was available,hemolytic autoimmune anemia $(n=1)$ responded after 1 month of treatment initiation [16], enteropathy improved between2 weeksto 2 months in three patients [8],whereas a singular more severe case required up to 12 monthsof therapy [17]. Resolution of diabetes mellitus was observedafter 12 months of ruxolitinib treatment in 1 case [10].

The IDDA score significantly decreased under ruxolitinib therapy (median pre: 15.99 , median post: 7.55, $\mathrm{p}=0.0078$ ), whilst P2 (patient under baricitinib) and P7 did not improve at 2 and 7 months, respectively(Table 1, Figure 2).

A summary of treatment responses reported for the previously published cases is shown in Figure 1. Although detailed descriptions were not available for all patients and symptoms, mostpatients showed improvement under therapy for the most prevalent disease manifestations such as CMC, enteropathy, cytopenias and lung disease.

\section{Prophylaxis and adverse events}

Antibacterial (5/10) and antiviral (2/10) prophylaxis and immunoglobulin replacement therapy $(5 / 10)$ were initiated prior toJAKinibsas part of theroutine clinical management. In addition,antimicrobial prophylaxis was started afterJAKinibinitiationin two patients; in P1 due to recurrent bacterial lower respiratory tract infectionsand in P8due to anticipated increased viral infection risk.

Bacterial infections (4 episodes during a 6-months period: 1 pneumonia and 3 episodes of upper respiratory tract infections with fever and acute reactants elevation), vertigo, sleep disturbances and transitory liver enzyme elevation were attributed by the attending physicians to theJAKinib as probable but not proved side effects (Table S-1). Treatment was discontinued in 3/10 patients. P6 and P9 stopped ruxolitinib due to hepatotoxicity just before HSCT and loss of effect on CMC respectively. P2 discontinued baricitinibas no treatment benefit was observed after two months of therapy.

In the previously reported 14 patients, 8 presented adverseevents potentially related to JAKinibs: 4/8 infections ( 2 cases varicella zostervirus, 1 herpes simplex virus and 1 cytomegalovirus(CMV) and 4/8 suffered from other complications (one each from thrombocytopenia and neutropenia and two from pancreatitis).

\section{Ruxolitiniband HSCT}

P6 (matched sibling donor) and P9 (matched unrelated donor) underwent HSCT. P5 is currently in the process of HSCT preparation. P6 was successfully transplanted and remains healthy and stable four years post-HSCT. P9 was treated twice with ruxolitinib therapy for eight months prior to HSCT, however the patient sadly deceased in the context of an uncontrollable thrombocytopenia and invasive aspergillosis 75 days post HSCT (complete donor chimerism, no signs of graft-versus-host disease). 
In three of the previously published 14 patients, ruxolitinib was stopped prior HSCT. In this setting, HSCT was successful in all reported cases.

\section{Discussion}

To the best of our knowledge, this is the most extensive pediatric case seriesdescribing patients with STAT1 GOF mutations under JAKinib therapyto date. Our study provides a detailed description of the clinical experience with this treatment approach in children and highlights the heterogeneity in terms of indications, dosing schedules and follow-up practices.

\section{Disease manifestations}

Infections were common in our cohort, correlating well with previous reports $[3,8,9,10,16,17]$. Before starting JAKinibs, most infections had been controlled; only P3 suffered fromCMV stomatitis. The previously published cases showed overall a more severe phenotype, with higher prevalence and severity of autoimmune manifestations and failure to thrive (Table 1). In addition, these patients had also received other immunosuppressive drugs. Thus, in most of themJAKinibs were not used as "first-line" therapy. In our series, JAKinibs were initiated at earlier disease stages, possiblyreflecting the positive experiences reported in the previous studies $[3,8,9,10,16,17]$.

\section{$\underline{\text { Indications }}$}

Reasons to start JAKinibs stated by the attendingphysicians of our cohort were similar to previous reports $[3,8,9,10,16,17]$. Beyond $C M C$, these included refractory autoimmune complications, progressive vasculopathy and lung disease (Table 1, Table S1). Furthermore, one patient received ruxolitinib for four months as a bridge to a subsequent HSCTprocedure[8, Table S-2].

\section{Treatment, dosing and treatment response}

In the setting of IEl, the appropriate dosing and interval remains to be established, as experience with these small molecule inhibitors in the pediatric age is very limited. Whilst the European Medicine Agency (EMA) has not yet approved ruxolitinib in children [18], the Food and Drug Administration (FDA) indicates their use for steroid-refractory acute graft-versus-host disease (GVHD) in children older than 12years of age in 2019 (recommended dose $5 \mathrm{mg}$ every 12 hours)[19]. $50 \mathrm{mg} / \mathrm{m}^{2} /$ dayhas been indicated to be the maximum well-tolerated dose in children [20]. Based on serial drug level determination and functional assays, 8 hours dose intervals have been recently suggested in a child with STAT3 GOF mutation associated with immune dysregulation (type 1 diabetes mellitus and interstitial lung disease). Interestingly, the dose needed and tolerated in this case report was high $(2.2 \mathrm{mg} / \mathrm{kg} /$ day $)$, being more than twice the dose compared to previous reports $[8,21]$ and those used in our own cohort (see Table S-1 and S-2). 
In our patients,ruxolitinib was used in $9 / 10$ and barcitinib in 1/10 child, respectively. The attending physicians preferred ruxolitinib, given the larger literary experience in STAT1 GOF setting. We provide detailed dosing information (Table 1 and Table S-1) for our patients, including the starting and maximum doses. Our starting $(0.28 \mathrm{mg} / \mathrm{kg} /$ day vs $0.8 \mathrm{mg} / \mathrm{kg} /$ day $)$ and maximum doses $(0.6 \mathrm{mg} / \mathrm{kg} /$ day vs 1.05 $\mathrm{mg} / \mathrm{kg} /$ day) were lower than previously reported $[3,8,9,10,16]$. However, the absence of homogenous protocols(and dosing reported diversely as $\mathrm{mg} / \mathrm{kg} / \mathrm{d}, \mathrm{mg} /$ day and $/ \mathrm{or}^{2} /$ day) in the literature limits conclusive comparisons and should beunified in future studies.Dose adjustments in our cohort were performed mainly according to the clinical effect, absence of adverse events and in three cases supported by functional analysis using pSTAT1 stimulation assays (P3, P4, P9).

Collectively, CMC was the most prevalent disease manifestation $(n=23)$ and JAKinib treatment was effective in almost all patients (overall response rate 20/22, Figure 1) within 2-8 weeks of treatment.Contrastingly, Acker et al. recently described a patient with only transient responses to JAKinib, administeredfor CMC, enteropathy and cytopenia [17].Importantly, in our cohort, the only patient receiving baricitinib did not show clinical improvement resulting in its discontinuation and switch to ruxolitinib.

In the absence of controlled prospective data, we suggest starting pediatric patients on $0.3-0.5 \mathrm{mg} / \mathrm{kg} / \mathrm{day}$ of ruxolitinibtwice per dayand then progressively increasing the dose by $0.1-0.2 \mathrm{mg} / \mathrm{kg} /$ day every $2-4$ weeks until achieving the expected clinical effect or occurrence of relevant side effects keeping in mind the suggested maximum dose of $50 \mathrm{mg} / \mathrm{m}^{2} /$ day by Lohet al.[20].

For the clinician, the patients and family it is important to know when to expect the Jakinib treatment to take effect. In our cohort, the cytopenias and CMC responded rather promptly (1-8 weeks), whereas others, such as keratitis and autoimmune hepatitis, required prolonged treatment courses (4-8 months). No improvement or worsening of cerebral aneurysms was observedin two patients. Unfortunately, the information available in the literature regarding treatment responses is often unspecific and incomplete. Where such data were provided,the time to response wassimilar to what was observed in our cohort requiring several weeks of therapy to achieve improvement [Table S-1].

Despite the combined data presented here, the number of pediatric STAT1 GOF patients treated with JAKinibs is still small. Furthermore, it is likely that the time to response might vary depending on the organ involved, severity and duration of the diseaseand JAKinibdosage. Therefore, larger, detailed, and prospective patient cohorts will need to address these aspects more consistently.

Baricitinib, a potent JAK1/JAK2 inhibitor has shown good tolerability in rheumatologic diseases and other monogenic interferonopathies [22,23]. To date,one case report indicated efficacy in an adult patient with STAT1 GOF suffering from recurrent aphthae, as well as oral and esophageal $\mathrm{CMC}[24]$.Contrastingly, in our cohort P2 failed to show any improvement after two months of treatment with $4 \mathrm{mg} / \mathrm{m} 2$. Curiously, upon switching to ruxolitiniba fast, completeand sustained remission of CMCand partial remission ofaphthae after 3 months of treatment were observed. Whether baricitinibis inferior or not in the control of the disease manifestations in STAT1 GOF compared to ruxolitinib remains to be determined. 
Assessing_disease activity using immune deficiency and dy sregulation activity_(IDDA) score

The IDDA score is a promising tool to assess disease activity and burden in the setting of immune dysregulatory diseases $[14,15]$. It allows for intraindividual, longitudinal monitoring by using a number of relevant clinical parameters and has been added as a voluntary option to the European Society for Immunodeficiencies (ESID) registry [25]. We applied the score for the first time to patients with STAT1 GOF obtaining lower numbers (15.99) when compared to those reported for lipopolysaccharide (LPS)responsive and beige-like anchor protein (LRBA) deficient patients proceeding to transplant (32.9) or those remaining under conventional immunosuppressive therapy (20.8) (Table 1, [14]). A significant reduction in the IDDA score was observed after initiation of JAKinib therapy for all patients with initial IDDA score $>10$, suggesting a substantial decline in the disease activity due to JAKinib introduction.

\section{Adverse events and monitoring}

Overall, the occurrence of adverse events potentially related to JAK inhibition were rare in our cohort. In fact, only one patient experienced an increased frequency of bacterial infections. Contrastingly, the reports in the literature for STAT1 GOF on JAKinibmention higher rates of urinary infections $[26,27]$ and other less frequent infectious complications, such as herpes virus reactivation [27],tuberculosis and/or other atypical mycobacterial infections [26,27,28], JC virus (four fatal cases) [29,30,31,32], pneumocystis jiroveci[33], hepatitis B [34,35] and toxoplasmosis [36]. This discrepancy might be attributed to an earlier introduction of JAKinibs in our cohort compared to their predominant use asa rescue strategy following the failure of other immunosuppressive regimens in the previously reported cases $[3,8,10,16,17]$.

Although no published guidelines exist, we observed a surprisingly consistent approach chosen by the individual participating centers in terms of investigations performed prior and during JAKinib therapy (Figure S1, Table S1). These parameters most likely reflect concerns based on the published experience with JAKinibs in other scenarios, such as myelofibrosis, arthritis and graft versus host disease (GVHD), as well as STAT1 GOF cases [26,27], FDA and EMA recommendations $[18,19]$. They include screening for infectious complications and monitoring for organ toxicity.In the absence of an easy-to-perform assay to determine ruxolitinibserum levels and the lack of the well-defined correlation between drug levels and clinical response, other biomarkers have been explored to monitor the drug effect/clinical response, such as phosphorylated STAT1 levels (pSTAT1) and IL17 production in T lymphocytes (TH17). Whilst some studies suggest a correlation between normalization of these markers [3,11,37],others reported a clear discrepancy [5]. This might be due to differences in timing of sampling, sample preparation and assay protocols. In future studies, harmonized treatment and monitoring protocols are needed toconsistently evaluate the role of these and other biomarkers in patients with IEI underJAKinib therapy.

In our cohort drug levels were not performed.All participating centers stated an overall interest to perform JAKinibs level testing but did not have test availability at their institutions.

Importantly, none of the patients described here experienced severe adverse events such as thromboembolism or pulmonary hypertension. Interestingly,one patient (P4), who was started on 
ruxolitinib despite suffering from pulmonary hypertension, showed a marked improvementallowingthe reduction of chronic medication forpulmonary hypertension, as well as the suspension oflong-term oxygen supplementation.

Our recommendation prior to starting the JAK inhibition in pediatric patients with STAT1 GOF is toobtain a complete medical history,aimingto identify previous, active or chronic infections and potential underlying organ damage. We also suggest applying early and extensive diagnostic and therapeutic strategies when suspecting viral, bacterial and/or fungal infections including blood, urine, stool, aspirate samplesand biopsies from affected tissues/organs, if indicated, to minimize the risk of severe and preventable infectious complications.

In the specific setting of JAK inhibition in (pediatric) STAT1 GOF patients, the role of primary or secondary antimicrobial, antiviral and antifungal prophylaxis remains to be established. Most authors suggest antimicrobial prophylaxis in patients with recurrent (respiratory) infections[38]. Systematic prevention of herpes virus infections is more controversial but should be considered in those patients with a history of systemic infection, severe lymphopenia as well as a history of long-term immunosuppression. In our cohort, immunoglobulin replacement therapy, antimicrobial and antiviral prophylaxis were prescribed according to the initial immunological work-up andwere not part of a specific strategy to prevent infections under JAKinib therapy.

\section{Conclusions}

We provide a comprehensive overview of the spectrum of pediatric STAT1 GOF patients that have been treated with JAK inhibitors to date, thereby highlighting the heterogeneity in terms of treatment indication, dosing and monitoring. Based on our experience and previously published reports, we have stated recommendations regarding dosing, monitoring and follow up tohelp guide the attending clinicians. Application of a standardized methodology aimed to systematically assess the JAKinibsindications, role of biomarkers and drug level determination as well as clinical responses are needed and should be included in future studies. In this regard,European Society for Immunodeficiency (ESID) and European Society for Blood and Marrow transplantation (EBMT) have recentlylaunched a multicentric retrospective study on JAKinib treatment in patients with inborn errors of the JAK/STAT pathways[39].

\section{Declarations}

\section{Acknowledgement:}

The authors would like to thank the patients and their families for participating in this study.

\section{Funding}

This work was supported bythe Job Research Foundation (NY, United States);the Consejería de Salud de la Junta de Andalucía (SA0051/2020 to O.N.); Agencia de Innovación y Desarrollo de Andalucía (PI-0184- 
2018 to P.O), Instituto de Salud Carlos III, Madrid, Spain [Sara Borrell, CD20/00124 to P.B.L, Juan Rodés JR18/00042 to P.O, FIS PI19/01471 to O.N. and P.O]; the projects PI18/00223, FI19/00208 and PI21/00211 to LA, integrated in the Plan Nacional de I+D+I and co- financed by the ISCIII - Subdirección General de Evaluación y Fomento de la Investigación Sanitaria - and the FondoEuropeo de Desarrollo Regional (FEDER), by PlaEstratègic de Recercailnnovacióen Salut (PERIS), Departament de Salut, Generalitat de Catalunya (SLT006/17/ 00199 to LA), by a 2017 Leonardo Grant for Researchers and Cultural Creators, BBVA Foundation (IN[17]_BBM_CLI_0357) to LA, by a 2017 Beca de Investigación de la Sociedad Española de InmunologíaClínicaAlergología y Asma Pediáatrica to LA, by a 2021 Beca de Investigación de la Sociedad Española de InmunologíaClínica, Alergología y Asma Pediátrica to ADM and by the Ministry of Health, Czech Republic [NV18-05-00162 to M.B and NV19-05-00332 to V.K]

\section{Financial interests}

All authors declare they have no financial interests related to this work.

\section{Authors contribution}

O. Neth, P. Olbrich and A. Deyà-Martínez have contributed to the study conception and design. Material preparation, data collection and analysis were performed by P. Olbrich, A. Deyà-Martínez, JG Rivière, P. Roxo-Junior, J. Ramakers, M. Bloomfield M, P. Guisado Hernandez, P. Blanco Lobo, S. Abu Rama,A. Esteve-Solé, V. Kanderova,A. García-García, M. Lopez-Corberto, N. Martinez Pomar, A. Martín-Nalda and L. Alsina. The first draft of the manuscript was written by P. Olbrich, A. Deyà-Martínez and 0 . Neth. All authors commented on previous versions of the manuscript. All authors read and approved the final manuscript.

\section{Data availability}

The datasets generated during and analysed during the current study are available from the corresponding author on reasonable request.

\section{Ethics approval}

The protocol of this study was reviewed and approved by the ethics committee "HospitalesUniversitarios Virgen Macarena y Virgen del Rocío" (PI19/01471; Cl 0641-N-20) and when applicable by the local ethics committees of the participating centers. Informed consents were obtained from study participants and/or their legal guardians according to the requirements of the local ethics committees.

\section{Consent to participate and publish}

The authors affirm that human research participants or their legal guardians provided informed consent for participation and publication of their individual details.

\section{References}


1. van der Veerdonk FL, Plantinga TS, Hoishchen A, Smeekens SP, Joosten LAB, Gilissen C, et al. STAT1 mutations in autosomal dominant chronic mucocutaneous candidiasis. $\mathrm{N}$ Engl $\mathrm{J}$ Med. 2011;365(1):54-61. doi: 10.1056/NEJMoa1100102

2. Liu L, Okada S, Hong XF, Kreins AY, Cypowyj S, Abhyankar A, et al. Gain-of- function human STAT1 mutation impair IL-17 immunity and underlie chronic mucocutaneous candidaisis. J Exp Med. 2011;208:1635-1648. doi: 10.1084/jem.20110958.

3. Al Shehri T, Gilmour K, Gothe F, Loughlin S, Bibi S, Rowan AD, et al. .Novel Gain-of-Function Mutation in Stat1 Sumoylation Site Leads to CMC/CID Phenotype Responsive to Ruxolitinib.J Clin Immunol. 2019;39(8):776-785. doi: 10.1007/s10875-019-00687-4.

4. Kiu H, Nicholson SE. Biology and significance of the JAK/STAT signaling pathways. Growth Factors. 2012;30(2):88-106. doi:10.3109/08977194.2012.660936

5. Zimmerman O, Olbrich P, Freeman AF, Rosen LB, Uzel G, Zerbe CS, et al. STAT1 Gain-of-Function Mutations Cause High Total STAT1 Levels With Normal Dephosphorylation. Front Immunol. $2019 \mathrm{Jul}$ 10;10:1433. doi.org/10.3389/fimmu.2019.01433

6. Toubiana J, Okada S, Hiller J, Oleastro M, Lagos Gomez M, Aldave Becerra JC, et al..Heterozygous STAT1 gain-of-function mutations underlie an unexpectedly broad clinical phenotype. Blood. 2016; ;127(25):3154-64. doi: 10.1182/blood-2015-11-679902.

7. Leiding JW, Okada S, Hagin D, Abinun M, Shcherbina A, Balashov DN, et al. Hematopoietic stem cell transplantation in patients with gain-of-function signal transducer and activator of transcription 1 mutations. J Allergy Clin Immunol.. 2018;141(2):704-717.e5. doi: 10.1016/j.jaci.2017.03.049

8. Forbes LR, Vogel TP, Cooper MA, Castro-Wagner J, Schussler E, Weinacht KG, et al. .Jakinibs for the treatment of immune dysregulation in patients with gain-of-function signal transducer and activator of transcription 1 (STAT1) or STAT3 mutations. J Allergy Clin Immunol. 2018;142(5):1665-1669. doi: 10.1016/j.jaci.2018.07.020

9. Moriya K, Suzuki T, Uchida N, Nakano T, Katayama S, Irie M, Rikiishi T, Niizuma H, Okada S, Imai K, Sasahara Y, Kure S. Ruxolitinib treatment of a patient with steroid-dependent severe autoimmunity due to STAT1 gain-of-function mutation. Int J Hematol. 2020 Aug;112(2):258-262. doi: $10.1007 / \mathrm{s} 12185-020-02860-7$

10. Chaimowitz NS, Ebenezer SJ, Hanson IC, Anderson M, Forbes LR. STAT1 Gain of Function, Type 1 Diabetes, and Reversal with JAK Inhibition. N Engl J Med. 2020t 8;383(15):1494-1496. doi: 10.1056/NEJMc2022226

11. Bloomfield M, Kanderová V, Paračková Z, Vrabcová $P$, Svatoň $M$, Froňková $E$, et al. Utility of Ruxolitinib in a Child with Chronic Mucocutaneous Candidiasis Caused by a Novel STAT1 Gain-ofFunction Mutation. J Clin Immunol. 2018;38(5):589-601. doi: 10.1007/s10875-018-0519-6

12. Neven B, Al Adba B, Hully M, Desguerre I, Pressiat C,Boddaert N, et al. JAK Inhibition in the AicardiGoutières Syndrome. New England Journal of Medicine, Massachusetts Medical Society, 2020, 383 (22), pp.2190-2193. doi:10.1056/NEJMc2031081 
13. Hadjadj J, Frémond ML, Neven B. Emerging Place of JAK Inhibitors in the Treatment of Inborn Errors of Immunity. Front Immunol. 2021; 17;12:717388. doi: 10.3389/fimmu.2021.717388.

14. Tesch VK, Abolhassani H, Shadur B, Zobel J, Mareika Y, Sharapova S, et al. Long-term outcome of LRBA deficiency in 76 patients after various treatment modalities as evaluated by the immune deficiency and dysregulation activity (IDDA) score. J Allergy Clin Immunol. 2020 May;145(5):14521463. doi: 10.1016/j.jaci.2019.12.896

15. Seidel MG, Tesch VK, Yang L, Hauck F, Horn AL, Smolle MA, et al The Immune Deficiency and Dysregulation Activity (IDDA2.1 'Kaleidoscope') Score and Other Clinical Measures in Inborn Errors of Immunity. J Clin Immunol. 2021 Nov 19. doi: 10.1007/s10875-021-01177-2. Epub ahead of print

16. Kayaoglu B, Kasap N, Yilmaz NS, Charbonnier LM, Geckin B, Akcay A, et al. Stepwise Reversal of Immune Dysregulation Due to STAT1 Gain-of-Function Mutation Following Ruxolitinib Bridge Therapy and Transplantation. J Clin Immunol. 2021 May;41(4):769-779. doi: 10.1007/s10875-02000943-y.

17. Acker KP, Borlack R, luga A, Remotti HE, Soderquist CR, Okada S, et al. Ruxolitinib Response in an Infant With Very-early-onset Inflammatory Bowel Disease and Gain-of-function STAT1 Mutation. J Pediatr Gastroenterol Nutr. 2020 Oct;71(4):e132-e133. doi: 10.1097/MPG.0000000000002854.

18. Full prescribing information JAKAVI EMA. https://www.ema.europa.eu/en/documents/productinformation/jakavi-epar-product-information_es.pdf. Accessed 04/08/2021.

19. Full prescribing information FDA: JAKAVI https://www.accessdata.fda.gov/drugsatfda_docs/label/2019/202192s017lbl.pdf. Accessed 04/08/2021.

20. Loh ML, Tasian SK, Rabin KR, Brown P, Magoon D, Reid JM, et al. A phase 1 dosing study of ruxolitinib in children with relapsed or refractory solid tumors, leukemias, or myeloproliferative neoplasms: A Children's Oncology Group phase 1 consortium study (ADVL1011). Pediatr Blood Cancer. 2015;62(10):1717-24. doi: 10.1002/pbc.25575.

21. Wegehaupt O., Muckenhaupt T., Johnson M.B. et al. Ruxolitinib Controls Lymphoproliferation and Diabetes in a STAT3-GOF Patient. J Clin Immunol 40, 1207-1210 (2020). https://doi.org/10.1007/s10875-020-00864-w

22. Sanchez GAM, Reinhardt A, Ramsey S, Wittkowski H, Hashkes PJ, Berkun Y, et al. JAK1/2 inhibition with baricitinib in the treatment of autoinflammatory interferonopathies. $J$ Clin Invest. 2018;128(7):3041-3052. doi: 10.1172/JCl98814.

23. Vanderver A, Adang L, Gavazzi F, McDonald K, Helman G, Frank DB, et al. Janus Kinase Inhibition in the Aicardi-Goutières Syndrome. N Engl J Med. 2020;383(10):986-989. doi: 10.1056/NEJMc2001362.

24. Meesilpavikkai K, Dik WA, Schrijver B, Nagtzaam NMA, Posthumus-van Sluijs SJ, van Hagen PM, et al. Baricitinib treatment in a patient with a gain-of-function mutation in signal transducer and activator of transcription 1 (STAT1). J Allergy Clin Immunol. 2018;142(1):328-330.e2. doi: 10.1016/j.jaci.2018.02.045. 
25. Registry Working Party. Immune Deficiency and Dysregulation Activity (IDDA) score. https://esid.org/Working-Parties/Registry-Working-Party/Studies/IDDA-Score. Accessed: 20 December 2021

26. Przepiorka D, Luo L, Subramaniam S, Qiu J, Gudi R, Cunningham LC, et al FDA Approval Summary: Ruxolitinib for Treatment of Steroid-Refractory Acute Graft-Versus-Host Disease. Oncologist. 2020;25(2):e328-e334. doi: 10.1634/theoncologist.2019-0627

27. Saeed I, McLornan D, Harrison CN. Managing side effects of JAK inhibitors for myelofibrosis in clinical practice. Expert RevHematol. 2017;10(7):617-625. doi: 10.1080/17474086.2017.1337507.

28. Sant'Antonio E, Bonifacio M, Breccia M, Rumi E. A journey through infectious risk associated with ruxolitinib. Br J Haematol. 2019;187(3):286-295. doi: 10.1111/bjh.16174.

29. Ballesta B, González H, Martín V, Ballesta JJ. Fatal ruxolitinib-related JC virus meningitis.JNeurovirol. 2017;23(5):783-78. doi: 10.1007/s13365-017-0558-4.

30. Nakayama K, Nakamura M, Konishi A, Kaneko S, Nakamichi K, Saijo M, Yakushiji Y, Kusaka H. JC virus granule cell neuronopathy associated with Ruxolitinib: A case report and review of the literature. eNeurologicalSci. 2020;21:100269 . doi: 10.1016/j.ensci.2020.100269

31. Reoma LB, Trindade CJ, Monaco MC, Solis J, Montojo MG, Vu P, et al A. Fatal encephalopathy with wild-type JC virus and ruxolitinib therapy. Ann Neurol. 2019;86(6):878-884. doi: 10.1002/ana.25608

32. Wathes R, Moule S, Milojkovic D. Progressive multifocal leucoencephalopathy associated with ruxolitinib. N Engl J Med. 2013;369:197-198. doi: 10.1056/NEJMc1302135

33. Lee SC, Feenstra J, Georghiou PR. Pneumocystis jiroveci pneumonitis complicating ruxolitinib therapy. BMJ Case Rep. 2014;2014. pii: bcr2014204950. doi: 10.1136/bcr-2014-204950

34. Gill H, Leung GMK, Seto WK, Kwong YL. Risk of viral reactivation in patients with occult hepatitis $B$ virus infection during ruxolitinib treatment. Ann Hematol. 2019;98(1):215-218. doi: 10.1007/s00277018-3405-7.

35. Caocci G, Murgia F, Podda L, Solinas A, Atzeni S, La Nasa G. Reactivation of hepatitis B virus infection following ruxolitinib treatment in a patient with myelofibrosis. Leukemia. 2014;28(1):225-7. doi: 10.1038/leu.2013.235.

36. Goldberg RA, Reichel E, Oshry LJ. Bilateral toxoplasmosis retinitis associated with ruxolitinib. $\mathrm{N}$ Engl J Med. 2013;369:681-683. doi: 10.1056/NEJMc1302895

37. Weinacht KG, Charbonnier LM, Alroqi F, Plant A, Qiao Q, Wu Het al. .Ruxolitinib reverses dysregulated $T$ helper cell responses and controls autoimmunity caused by a novel signal transducer and activator of transcription 1 (STAT1) gain-of-function mutation. J Allergy Clin Immunol. 2017;139(5):16291640.e2. doi: 10.1016/j.jaci.2016.11.022.

38. Cordero E, Goycochea-Valdivia W, Mendez-Echevarria A, Allende LM, Alsina L, Bravo García-Morato $\mathrm{M}$, et al. Executive Summary of the Consensus Document on the Diagnosis and Management of Patients with Primary Immunodeficiencies. J Allergy Clin Immunol Pract. 2020;8(10):3342-3347. doi: 10.1016/j.jaip.2020.05.008. 
39. Registry Working Party. Resources. https://esid.org/Working-Parties/Inborn-Errors-Working-PartyIEWP/Studies/Multicentric-retrospective-study-on-JAKinib-treatment-of-patients-with-IEI-of-the-JAKSTAT-pathway. Accessed 21 December 2021

\section{Tables}

Table 1. Summary of baseline characteristics $(n=10)$ 


\begin{tabular}{|c|c|c|}
\hline & $\mathrm{n}=10$ * & $\begin{array}{l}\text { Literature review } \\
n=14\end{array}$ \\
\hline Age (years) at time of study entry: mean & 8.5 y $(3 y-18 y)$ & $10 y(7 m-17 y)$ \\
\hline Gender (female) & $8 / 10$ & $7 / 14$ \\
\hline Age (months) at symptom onset & $6(1-48)$ & $4(0.5-10)^{\star \star}$ \\
\hline \multicolumn{3}{|l|}{ Mutations localization } \\
\hline Coiled Coil Domain & $4 / 10$ & $2 / 14$ \\
\hline DNA Binding Domain & $5 / 10$ & $8 / 14$ \\
\hline Linker Domain & $0 / 10$ & $2 / 14$ \\
\hline SH2 Domain & $1 / 10$ & $1 / 14$ \\
\hline Tail Segment Domain & $0 / 10$ & $1 / 14$ \\
\hline Infections prior JAK inhibitor & $10 / 10$ & $14 / 14$ \\
\hline Viral & $7 / 10$ & $5 / 14$ \\
\hline Fungal & $10 / 10$ & $13 / 14$ \\
\hline Bacterial & $8 / 10$ & $11 / 14$ \\
\hline Only CMC & $2 / 10$ & $0 / 14$ \\
\hline Autoimmunity and autoinflammation & $10 / 10$ & $12 / 14$ \\
\hline Cytopenia & $3 / 10$ & $9 / 14$ \\
\hline Enteropathy & $2 / 10$ & $8 / 14$ \\
\hline Autoimmune hepatitis & $1 / 10$ & $6 / 14$ \\
\hline Endocrinopathy & $0 / 10$ & $4 / 14$ \\
\hline Oral aphthae & $8 / 10$ & $2 / 14$ \\
\hline Arthritis & $1 / 10$ & $0 / 14$ \\
\hline Keratitis/episcleritis & $4 / 10$ & $1 / 14$ \\
\hline Dermatitis/eczema & $2 / 10$ & $2 / 14$ \\
\hline Fatigue & $2 / 10$ & $1 / 14$ \\
\hline Alopecia & $0 / 10$ & $2 / 10$ \\
\hline Lymphoproliferation & $0 / 10$ & $1 / 14$ \\
\hline Pulmonary disease & $6 / 10$ & $5 / 14^{\&}$ \\
\hline Bronchiectasis & $6 / 10$ & $5 / 14$ \\
\hline
\end{tabular}


Interstitial lung disease

Pulmonary hypertension

Failure to thrive

Vasculopathy

Heart

Nervous central system

Antibody deficiency*k*

Subclasses deficiency and hypo IgM and $\lg \mathrm{A}$

Subclasses deficiency and hypo IgA

Isolated low IgM

SPAD

Hypo IgG and SPAD

Isolated low IgG

Subclasses deficiency

Isolated low IgA
$0 / 10$
$0 / 14$

$1 / 10$

$0 / 14$

$3 / 10$

$9 / 14$

$2 / 10$

$1 / 14$

0

$0 / 14$

$2 / 2$

$1 / 14$

$5 / 10$

$3 / 14$

HSCT

Mortality

JAK inhibitor information

Type of JAK inhibitor

Ruxolitinib

$9 / 10$

$14 / 14$

Baricitinib

Starting Dosage: median (range)

Ruxolitinib

Baricitinib

Maximum dosage: median (range)

Ruxolitinib
$2 / 10$

$1 / 10$
$1 / 10$

$0.28(0.2-0.6)$

$\mathrm{mg} / \mathrm{kg} /$ day

$2 \mathrm{mg} /$ day

$0.6(0.25-0.78)$

$\mathrm{mg} / \mathrm{kg} /$ day

$4 \mathrm{mg} /$ day
0

0

0

0

1

1

1

$4 / 14$

$0 / 14$
$0 / 14$

20 (5-50) mg/day 11/14

$5(5-5) \mathrm{mg} / \mathrm{m}^{2} /$ day $3 / 14$

20 (5-50) mg/day (11/14)

$10(10-15) \mathrm{mg} / \mathrm{m}^{2} /$ day

$(3 / 14)$

Baricitinib

Reason to start JAK inhibitors ${ }^{\text {\& }}$

$4 / 10$

$3 / 14$

$1 / 10$

$1 / 14$ 


$\begin{array}{lcc}\text { Uncontrolled immune dysregulation } & 1 / 10 & 6 / 14 \\ \text { Oral aphthae } & 1 / 10 & 2 / 14 \\ \text { Keratitis/iritis } & 1 / 10 & 4 / 14 \\ \text { Enteropathy } & 0 / 10 & 1 / 14 \\ \text { Autoimmune hepatitis } & 0 / 10 & 2 / 14 \\ \text { Autoimmune Cytopenia } & 0 / 10 & 1 / 14 \\ \text { Fatigue } & 0 / 10 & 2 / 14 \\ \text { Type I Diabetes mellitus } & 1 / 10 & 0 / 10 \\ \text { Alopecia } & 0 / 10 & 1 / 14 \\ & 6 / 10 & 4 / 14\end{array}$

Failure to thrive

$2 / 10$

ND

Life threatening infections

$4 / 10$

ND

Recurrent bacterial infections

$2 / 10$

$1 / 14$

Chronic mucocutaneous candidiasis

$2 / 10$

$0 / 14$

Azole resistant

$1 / 10$

$1 / 14$

Azole susceptible

Vasculopathy progression

Lung disease progression/decline lung

function

Bridge to HSCT

Median follow up in months (range)

$18(2-42)$

ND

Median IDDA Score (range)

$15.99(5.2-40)$

Before treatment

7.55 (3-14.1)

Under treatment

$p=0.0078$

ND

Side effects

$4 / 10$

Infectious

$1 / 4$

$4 / 14$

other

$3 / 4$

$4 / 14$

Stop JAK Inhibitor

$3 / 10$

ND

CVID: common variable immunodeficiency;HSCT: hematopoietic stem cell transplantation; IDDA: immune deficiency and dysregulation activity; m: months; ND: No detailed information was available for this variable. SPAD: Specific polysaccharide antibody deficiency; y: year * The results are expressed by 
median and range (min-max) and percentage if not stated otherwise. **Information available only from 4 patients. ${ }^{* \star}$ Some patients presented more than one humoral defect. ${ }^{\&}$ One of these patients was stated to suffer from an unspecified chronic lung disease. \&\&Patients may have more than one reason to start Ruxolitinib

\section{Figures}

\begin{tabular}{|c|c|c|c|c|c|c|c|c|c|c|c|c|c|c|c|c|c|c|c|c|c|c|c|c|c|}
\hline \multirow[b]{2}{*}{$\begin{array}{l}\text { Patient number in } \\
\text { publication }\end{array}$} & \multicolumn{11}{|c|}{ Deya et al (this cohort) } & \multicolumn{8}{|c|}{ Forbes et al [8] } & \multirow{2}{*}{$\begin{array}{c}\begin{array}{l}\text { Moriya } \\
\text { et al [9] }\end{array} \\
1\end{array}$} & \multirow{2}{*}{$\begin{array}{c}\text { Chaimowitz } \\
\text { et al [10] }\end{array}$} & \multirow{2}{*}{$\begin{array}{c}\begin{array}{l}\text { Al Shehri } \\
\text { et al [3] }\end{array} \\
1\end{array}$} & \multirow{2}{*}{$\begin{array}{c}\text { Kayaoglu } \\
\text { et ol [16] }\end{array}$} & \multirow{2}{*}{$\begin{array}{l}\text { Acker } \\
\text { et al } \\
{[15]} \\
1\end{array}$} & \multirow{2}{*}{$\begin{array}{l}\text { Overall } \\
\text { response } \\
\text { rate* }\end{array}$} \\
\hline & 1 & 2 & 3 & 4 & 5 & 6 & 7 & 8 & 9.1 & 9.2 & 10 & \begin{tabular}{l|l}
1 & 3 \\
\end{tabular} & \begin{tabular}{|l|l|}
3 & 4 \\
\end{tabular} & 5 & 7 & 8 & 9 & 10 & 11 & & & & & & \\
\hline Follow up (m) & 28 & 2 & 39 & 42 & 18 & $4^{* *}$ & 7 & 30 & 8 & 10 & 9 & & & & & & & & & & ND & & & & \\
\hline CMC & & & & & & & & & & & & & & & & & & & & & & & & & $18 / 22$ \\
\hline $\begin{array}{l}\text { Enteropathy/Diarr } \\
\text { hea }\end{array}$ & & & & & & & & & & & & & & & & & & & & & & & & & $11 / 12$ \\
\hline Stomatitis/Ulcers & & & & & & & & & & & & & & & & & & & & & & & & & $7 / 8$ \\
\hline Urticaria/skin rash & & & & & & & & & & & & & & & & & & & & & & & & & $5 / 5$ \\
\hline Lung disease & & & & & & & & & & & & & & & & & & & & & & & & & $5 / 5$ \\
\hline Cytopenia & & & & & & & & & & & & & & & & & & & & & & & & & $3 / 9$ \\
\hline Aneurysm & & & & & & & & & & & & & & & & & & & & & & & & & $0 / 3$ \\
\hline Alopecia & & & & & & & & & & & & & & & & & & & & & & & & & $1 / 2$ \\
\hline LFTs/Al hepatitis & & & & & & & & & & & & & & & & & & & & & & & & & $3 / 5$ \\
\hline Keratitis / Iritis & & & & & & & & & & & & & & & & & & & & & & & & & $3 / 3$ \\
\hline Fatigue & & & & & & & & & & & & & & & & & & & & & & & & & $5 / 5$ \\
\hline DM type 1 & & & & & & & & & & & & & & & & & & & & & & & & & $1 / 3$ \\
\hline
\end{tabular}

\footnotetext{
This cohort:

Dark Green: Complete response

Green: $\quad$ Partial response

Red: $\quad$ No response

Literature review:

Black: $\quad$ Complete or partial response

Gray: $\quad$ Symptom or manifestation present in the patient but response to Jakinib not specified

White: $\quad$ Symptom or manifestation not present at time of Jakinib initiation

Blue: $\quad$ Transient response
}

Al: autoimmune; CMC: chronic mucocutaneous candidiasis; DM: diabetes mellitus; LFT: liver function tests; m: month; ND: No detailed information was available for this variable.

*Overall response rate was defined as sustained improvement of symptoms (when present) stated by the investigators.

**4 months after Ruxolitinib and 8 years post hematopoietic stem cell transplantation

\section{Figure 1}

Response to JAK inhibitor treatment 


\section{Ruxolitinib effect}

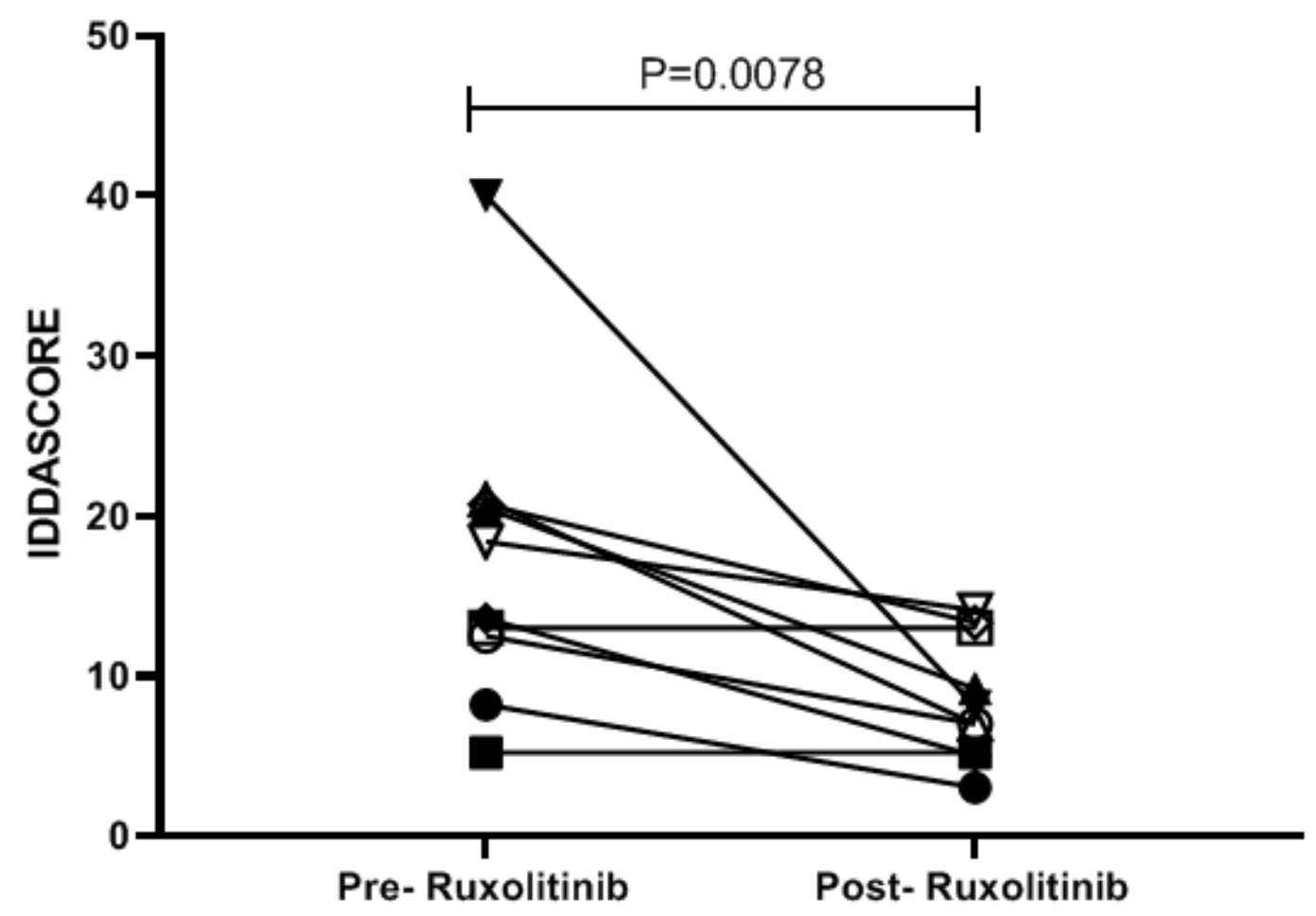

- Patient 1

- Patient 2

¿ Patient 3

7 Patient 4

$\downarrow$ Patient 5

$\vartheta$ Patient 6

$\boxminus$ Patient 7

$\triangle$ Patient 8

7 Patient 9

$\diamond$ Patient 10

Figure 2

Effect of JAKinibs on Immune deficiency and dysregulation activity (IDDA) score

\section{Supplementary Files}

This is a list of supplementary files associated with this preprint. Click to download.

- STAT1GOFsuppltableandfiguresDeyaMartinezetal.docx 